\title{
Measuring The Functional Outcomes Following Open Carpal Tunnel Release in Patients Coming in the Ortho OPD of Dr. Hardas Singh Orthopedic Hospital And Superspeciality Research Centre Circular Road Amritsar, PUNJAB with The Diagnosis of Carpal Tunnel Syndrome
}

\author{
Dr. Pancham Prasad", Dr. Parvinder Singh Sandhu
}

HOD, Dept. of Orthopedic Dr. Hardas Singh Orthopedic Hospital and Superspeciality Research Centre Circular Road Amritsar, Punjab India

DOI: $10.36347 /$ sajb.2020.v08i10.004

| Received: 01.10.2020 | Accepted: 08.10.2020 | Published: 15.10.2020

*Corresponding author: Dr. Pancham Prasad

\section{Abstract}

\section{Original Research Article}

Background: Carpal tunnel syndrome (CTS) is the most commonly observed entrapment neuropathy. An Extremely frequent forearm neuropathy occurring in the carpal tunnel of the wrist due to median nerve trapping. With an aim to record the results of the open carpal tunnel release in patients willing to participate in the study, this was planned with certain objectives 1 . To know the demography of the attending patients with complaints 2 . To ascertain the functional outcome after the Open Carpal Tunnel Release in patients of Carpal Tunnel Syndrome. Methodology: A prospective study design was employed after appropriate approval in our institute from IEC body. The study was done starting Dec 2019 till Feb 2020. After 6 weeks, 3 months and 6 months, patients were followed up postoperatively. All subjects were produced preoperatively and at each follow-up visit to fill out the Quick DASH form. Data Analysis - Data was inserted into Excel sheets, and using SPSS version 21 software, statistical analysis of the data was carried out. The mean \pm standard deviation was recorded as continuous data. Categorical data were reported as numbers and percentages and were analyzed using, as necessary, the Chi-square test or the exact Fisher test. The $\mathrm{P}<0.05$ value was considered statistically significant. Results: A total of 110 patients participated in this study with more females than males. Overall most of the patients were having hypothyroidism, both dominant and non-dominant upper arm were involved while a comparison between pre-operative and post-operative scores of Quick DASH test gave a strong statistically significant result. Conclusion: Carpal tunnel release is relatively easy, cost effective and patient friendly treatment option for all those who don't respond to drugs, mainly pain killers and steroids.

Keywords: Carpal Functional Outcomes Road Amritsar.

Copyright $\odot 2020$ The Author(s): This is an open-access article distributed under the terms of the Creative Commons Attribution 4.0 International License (CC BY-NC 4.0) which permits unrestricted use, distribution, and reproduction in any medium for non-commercial use provided the original author and source are credited.

\section{INTRODUCTION}

- Carpal tunnel syndrome (CTS) is the most commonly observed entrapment neuropathy. An Extremely frequent forearm neuropathy occurring in the carpal tunnel of the wrist due to median nerve trapping.

- $\quad$ Paget in 1854 described it for the first time. When he outlined a Median palsy of the nerve in a man after a fracture of the lower end of the radius. He thought the pressure on the radius. Was due to excess bone formation at the fracture site however the symptoms were managed by resting the wrist in a splint and they returned when they had used the wrist. The treatment of CTS was first proposed by sectioning the transverse carpal ligament in 1913 by Marie and Foix. The first definite case of median nerve surgical decompression was not confirmed up until 1933.
- The etiology of CTS is mainly systemic, hereditary, and biological, with environmental and occupational factors.

- The key symptom of CTS is the recurrent numbness of the thumb, index, long fingers, and radial half of the ring finger, While Paresthesia, discomfort and numbness in the distribution areas of the median nerve transmission are the most often associated symptoms of this disease encountered frequently in OPD settings of the Orthopedics Department.

- Females are more commonly affected on comparison in numbers with male. CTS are one of the most common disorders that contribute to function. Apart from CTS, Various conditions can cause wrist compression of the median nerve which can lead to ischemia of the median nerve. The signs and symptoms depend on the severity of the disorder. The initial characteristics are due to the 
involvement of the nerve's sensory portion and the later problems are due to the motor portion's involvement. A common complaint being seen is that patients are awakened by extreme pain during the middle of the night and often hang their hand out of their bed and shake it vigorously to relieve pain. Both forms of treatment are available as surgical treatment and non-surgical treatment, yet little information is available on the advantages of non-surgical treatment modalities. Patients with extreme advanced CTS, who are not receptive to conservative management, and other candidates who want not to ingest too many pain killers or steroids are treated with open surgery known as open carpal tunnel release, which produces good results.

- The key objectives for patients on each surgical treatment are the relief of pain, early recovery, cosmetic satisfaction and cost-effectiveness of the operation. Many of these approaches to the release of carpal tunnels meet these targets for patients.

- To ascertain the benefits of the treatment provided and document it quantitatively we relied on various available tools which are patient reported outcome measures.

- Out of these available tools we chose on to DASH and Quick dash test owing to their ease of testing, simple questions and ease of administration. However QUICK DASH test which is a shorter version of the DASH method and is more consistent was the winner for us to give to the patients in our settings as it was easily translated to Hindi the preferred language in these parts and during our pilot well received.

- Quick DASH's possible benefits include less pressure on respondents, the removal of issues that appear to have high non-response (e.g. sexual activities), and the opportunity to use the time saved to catch other essential constructs [11].

Though the procedure is accepted and globally practiced, evidence regarding the benefits it gives to patients in Dr. Hardas singh hospital is not documented and present on various research data bases.

With an aim to record the results of the open carpal tunnel release in patients, willing to participate in the study, this was planned, with these objectives

1. To know the demography of the attending patients with complaints

2. To ascertain the functional outcome after the Open Carpal Tunnel Release in patients of Carpal Tunnel Syndrome.

\section{METHODOLOGY}

- A prospective study design was employed after appropriate approval in our institute from IEC body. The study was done starting Dec 2019 till Feb 2020.

- Study was done In the Department of Orthopedics in Dr. Hardas Singh orthopedic hospital with a set of inclusion criterion on all willing patients.

- Based on clinical symptoms, signs, and nerve conduction tests, each patient was diagnosed with carpal tunnel compression neuropathy. Conservative therapy was initially provided, including rest, bracing, and nonsteroidal anti-inflammatory drugs. Patients that have been diagnosed with CTS within 3 years, were in good general health, had very slow results in nerve conduction but good muscle strength, and eventually had symptoms that are worse at night than in this study during the day were offered the surgical treatment option .

- This research removed those patients who have very serious symptoms such as constant numbness, muscle weakness and wasting, and very poor nerve conduction outcomes with other upper extremity problems and chronic underlying medical condition.

- Also patients with earlier treatment with carpal tunnel release were excluded from the study. Also excluded were pregnant female with median nerve compression were excluded from the study. A total of 110 patients were finally enrolled in this study.

- Brief Description of the Operative procedure- The affected hand, wrist, and forearm were washed with a povidone-iodine solution prior to surgery. With a sterile compress, the area to be worked was sealed. We used a pneumatic tourniquet. With a wrist extension of 30 degrees, the handhold in place by a cushion positioned under the wrist joint and with the thumb taken away, an optimal hand position was obtained. Local anaesthesia, then was done with 2 percent xylocain $5 \mathrm{cc}$ and isotonic SF $5 \mathrm{cc}$. A small opening was made with a fine scissor or surgical blade in the carpal ligament and a dissector was inserted under the carpal ligament, and then the ligament was cut with a surgical blade. The skin was sutured after homeostasis with a 4/0 suture mattress All the participants underwent open carpal tunnel release and median nerve neurolysis under local anaesthesia after preoperative evaluation.

- On the same day, the subjects were discharged. The Carpal tunnel splint was applied for 2 weeks post-operatively. After 6 weeks, 3 months and 6 months, patients were followed up postoperatively. All subjects were produced preoperatively and at each follow-up visit to fill out the Quick DASH form. 


\section{DATA ANALYSIS}

Data was inserted into Excel sheets, and using SPSS version 21 software, statistical analysis of the data was carried out. The mean \pm standard deviation was recorded as continuous data. Categorical data were reported as numbers and percentages and were analyzed using, as necessary, the Chi-square test or the exact Fisher test. The $\mathrm{P}<0.05$ value was considered statistically significant.

\section{RESULTS}

Our study had 110 participants with more females coming to the OPD for seeking treatment of carpal tunnel syndrome $(n=65,59 \%)$ while most were in the age group of 31-50. Mean age was 39.59 with std. deviation of 11.83. The correlation between age and gender was of statistical significance. (Tbale1)

Table-1: Relationship between Gender and Age Group was found to be of statistical significance

\begin{tabular}{|c|c|c|c|c|c|c|c|}
\hline Age of the Participants & Age Category & Male & & Female & & Total & \\
\hline \multirow{6}{*}{ Age In years } & $11-20$ & 5 & $11 \%$ & 7 & $11 \%$ & 12 & $11 \%$ \\
\hline & $21-30$ & 4 & $9 \%$ & 5 & $8 \%$ & 9 & $8 \%$ \\
\hline & $31-40$ & 10 & $22 \%$ & 18 & $28 \%$ & 28 & $25 \%$ \\
\hline & $41-50$ & 20 & $44 \%$ & 25 & $38 \%$ & 45 & $41 \%$ \\
\hline & $51-60$ & 5 & $11 \%$ & 10 & $15 \%$ & 15 & $14 \%$ \\
\hline & $61-70$ & 1 & $2 \%$ & 0 & $0 \%$ & 1 & $1 \%$ \\
\hline \multicolumn{2}{|l|}{ Total } & 45 & $41 \%$ & 65 & $59 \%$ & 110 & \\
\hline
\end{tabular}

- There was no incidence of local hematoma or nerve damage during the surgical process. There were no procedure-related complications during the follow-up period, such as skin infection, scar tenderness, excessive scar formation, and stiffness.

- All symptoms were alleviated shortly after surgery and it took all patients an average of 2 months to completely recover after surgery. We had more cases of both hands involved $(n=76,65 \%)$ while dominant with statistical significance, non-dominant and equally involved hands were also seen in fair distribution (Table 2). A relationship was also explored for gender and hypothyroidism between males and females $(35 \%$ were found to be having hypothyroidism statistically significant. While RH factors were also evaluated for and results mostly RH negative for both sexes $(n=82,75 \%)$.

- The final outcome was measured by the accepted patient outcome measure Quick DASH method. The pre-operative and post-operative scores were evaluated and were compared in the various classification scores obtained for all patients operated upon. It was found to be of high statistical significance.

Table-2: A brief description about the hands involved and their statistical significance

\begin{tabular}{|l|l|l|l|l|l|l|l|}
\hline \multicolumn{2}{|c}{} & Male & & Female & Total & \\
\hline Hands Involved & Single Hand & 18 & $40 \%$ & 16 & $25 \%$ & 34 & $31 \%$ \\
\cline { 2 - 8 } & Both Hand & 27 & $60 \%$ & 49 & $75 \%$ & 76 & $69 \%$ \\
\hline \multirow{3}{*}{ Dominant Hands Involved } & Dominant & 20 & $44 \%$ & 20 & $31 \%$ & 40 & $36 \%$ \\
\cline { 2 - 8 } & Non Dominant & 12 & $27 \%$ & 22 & $34 \%$ & 34 & $31 \%$ \\
\cline { 2 - 8 } & Equally Involved & 13 & $29 \%$ & 23 & $35 \%$ & 36 & $33 \%$ \\
\hline
\end{tabular}

Table-3: A brief Description with statistically significant results on association with diseased conditions

\begin{tabular}{|l|l|l|l|l|l|l|l|}
\hline & & Male & & Female & & Total & \\
\hline Thyroid Disorder & $\begin{array}{l}\text { Hypo } \\
\text { thyroidism }\end{array}$ & 18 & $40 \%$ & 20 & $31 \%$ & 38 & $35 \%$ \\
\cline { 2 - 9 } & Euthryoid & 27 & $60 \%$ & 45 & $69 \%$ & 72 & $65 \%$ \\
\hline \multirow{2}{*}{ RH Factor } & RH + & 12 & $27 \%$ & 16 & $25 \%$ & 28 & $25 \%$ \\
\cline { 2 - 9 } & RH - & 33 & $73 \%$ & 49 & $75 \%$ & 82 & $75 \%$ \\
\hline & 45 & 65 & & 110 & \\
\hline
\end{tabular}




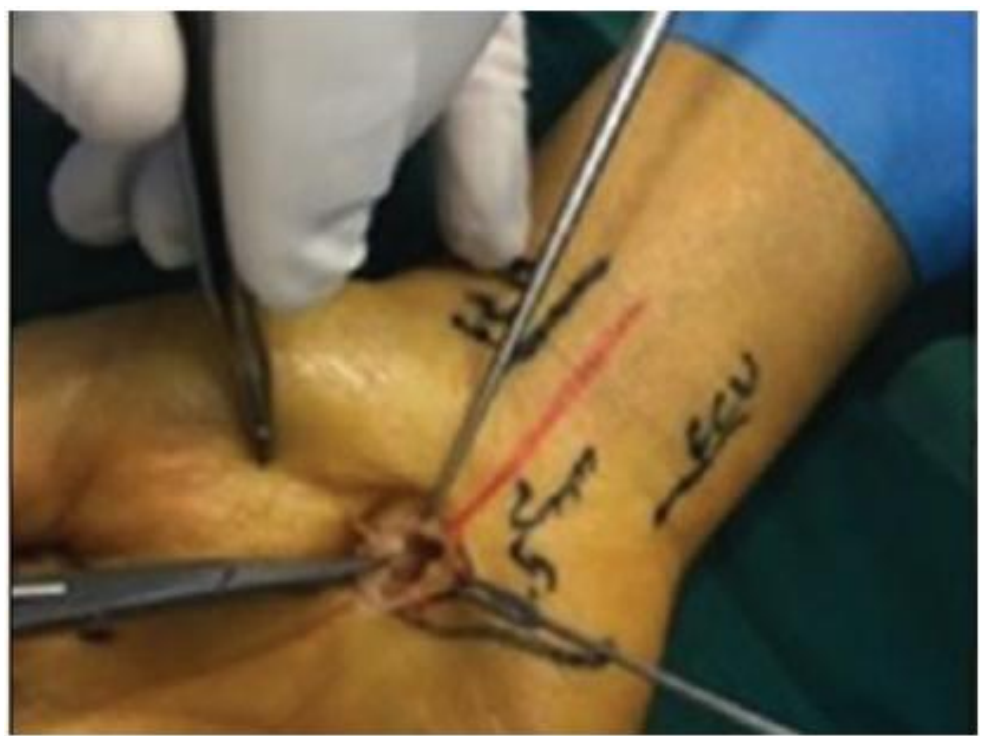

Fig-1: Open carpal Tunnel Release

Table-4: A comparison of Pre Op scores for all participants and Post Op Scores, $p$ <.001 signifies statistical significance of very high significance

\begin{tabular}{|l|l|l|l|l|l|}
\hline & Score Category & Pre -Op & & Post- Op & \\
\hline \multirow{3}{*}{ Quick DASH Score } & $0-25$ & 5 & $5 \%$ & 50 & $45 \%$ \\
\cline { 2 - 6 } & $26-50$ & 30 & $27 \%$ & 39 & $35 \%$ \\
\cline { 2 - 6 } & $51-75$ & 47 & $43 \%$ & 11 & $10 \%$ \\
\cline { 2 - 6 } & $76-100$ & 28 & $25 \%$ & 10 & $9 \%$ \\
\hline & Total participants & 110 & & 110 & \\
\hline
\end{tabular}

\section{DISCUSSION}

- The most common form of compression neuropathy is carpal tunnel syndrome, which accounts for approximately $90 \%$ of trapping neuropathies. Carpal tunnel syndrome is a symptomatic wrist area compression of the median nerve and is physiologically characterised by evidence of increased pressure inside the carpal tunnel and reduced median nerve function.

- Our analysis tests patients' functional rehabilitation following the release of the open carpal tunnel. In our study, the age range of study subjects ranged from 18 years of age to 68 years of age for the oldest. In the fourth and fifth decades, maximum patient numbers were identified.

- Studies by De Krom et al. and Nordstrom et al have shown that, with just $10 \%$ of subjects younger than 31 years, the most common age of development for carpal tunnel syndrome is 45-60 years. In our sample, female preponderance was comparable to most studies like by Mondelli et al. and Palmer et al. where the population of females in the series was $72 \%$ and $83 \%$, respectively.

- As per our details, hand dominance and its link to symptoms could not be associated. Whereas patients with systemic diseases such as thyroid and rheumatoid had bilateral involvement, most factory workers had dominant hand participation.
- Lam et al. have shown dominant hand involvement in factory workers. Our research has shown the association of hypothyroidism and rheumatoid arthritis with carpal tunnel syndrome. Many writers, including Boz et al.

- Mondelli et al. and many others have already well demonstrated these causes of carpal tunnel syndrome. Fast DASH scores have not been used as a functional parameter in patients with Carpal tunnel syndrome to date. The dramatic change in these scores after surgery indicates that the opening of the open carpal tunnel is a very successful and reproducible method of treating carpal tunnel syndrome.

\section{CONCLUSION}

An efficient and secure treatment is the surgical management of carpal tunnel syndrome with open carpal tunnel release. It is possible to consider the fast dash score as a reliable and useful method to determine the outcome of this surgical release. There were less early and late complications, including bleeding, discomfort, palm tenderness, scar irritation, stiffness, and minimal enhanced and cosmetic issues. In addition, with high patient satisfaction and low need for frequent therapy and recovery expenses, the transition to everyday life activities was shorter. This technique requires practice 
for best results. More data from other sites will validate our findings.

\section{REFERENCES}

1. Carpal Tunnel Syndrome. Yamaguchi dm, Lipscomb pr, Soule eh Minn Med. 1965 Jan; 48():22-33.

2. Ibrahim I, Khan WS, Goddard N, Smitham P. Carpal tunnel syndrome: A review of the recent literature. Open Orthop J. 6:69-76.

3. Disparity between popular (Internet) and scientific illness concepts of carpal tunnel syndrome causation. Scangas G, Lozano-Calderón S, Ring D J Hand Surg Am. 2008 Sep; 33(7):1076-80.

4. Current status of outcomes research in carpal tunnel surgery. Chung KC Hand (N Y). 2006 Jun; 1(1):9-13.

5. Measurement of pressure in the carpal canal before and after endoscopic management of carpal tunnel syndrome. Okutsu I, Ninomiya S, Hamanaka I, Kuroshima N, Inanami H J Bone Joint Surg Am. 1989 Jun; 71(5):679-83.

6. Carpal tunnel syndrome: morphologic changes after release of the transverse carpal ligament.Richman JA, Gelberman RH, Rydevik BL, Hajek PC, Braun RM, Gylys-Morin VM, Berthoty D, J Hand Surg Am. 1989 Sep; 14(5):852-7.

7. Smith MW, Ma J, Stafford RS and Bar charts enhance Bland-Altman plots when value ranges are limited. J Clin Epidemiol. 2010; 63: 180- 184

8. Michener LA, McClure PW, Sennett BJ and American Shoulder and Elbow Surgeons Standardized Shoulder Assessment Form, patient self-report section: reliability, validity, and responsiveness. J Shoulder Elbow Surg. 2002; 11: 587-594.

9. Bot SD, Terwee CB, van der Windt DA, Bouter LM, Dekker J, de Vet HC and Clinimetric evaluation of shoulder disability questionnaires: a systematic review of the literature. Ann Rheum Dis. 2004; 63: 335-341.

10. Beaton DE, Wright JG, Katz JN and Development of the QuickDASH: comparison of three item-reduction approaches. J Bone Joint Surg Am. 2005; 87: 1038- 1046.

11. Macdermid JC, Khadilkar L, Birmingham TB, Athwal GS. Validity of the QuickDASH in patients with shoulder-related disorders undergoing surgery. J Orthop Sports Phys Ther. 2015;45(1):25-36.

12. Turner A, Kimble F, Gulyas K, Ball J. Can the outcome of open carpal tunnel release be predicted?: A review of the literature. ANZ J Surg 2010; 80:50-4.

13. Keith MW, Masear V, Chung K, Maupin K, Andary M, Amadio PC, Barth RW, Watters WC, 3rd, Goldberg MJ, Haralson RH 3rd, Turkelson CM and Wies JL. Diagnosis of carpal tunnel syndrome. The Journal of the American Academy of Orthopaedic Surgeons. 2009; 17(6), 389-396.

14. De Krom MC, Kester AD, Knipschild PG, Spaans F. Risk factors for carpal tunnel syndrome. Epidemiology. 1990; 132(6):1102-10.

15. Nordstrom DL, DeStefano F, Vierkant RA, Layde PM. Incidence of diagnosed carpal tunnel syndrome in a general population. Epidemiology. 1998; 9(3):342-5.

16. Mondelli M, Giannini F, Giacchi M. Carpal tunnel syndrome incidence in a general population. Neurology. 2002; 58(2):289-94.

17. Palmer KT, Harris EC, Coggon D. Carpal tunnel syndrome and its relation to occupation: a systematic literature review. Occup Med (Lond). 2007; 57(1):57-66.

18. Boz C, Ozmenoglu M, Altunayoglu V, Velioglu S, Alioglu Z. Individual risk factors for carpal tunnel syndrome: an evaluation of body mass index, wrist index and hand anthropometric measurements. Clin Neurol Neurosurg. 2004; 106(4):294-9. 